\title{
Analysis of stainless steel samples by energy dispersive X-ray fluorescence (EDXRF) spectrometry
}

\author{
M K TIWARI*, A K SINGH and K J S SAWHNEY \\ Synchrotron Utilization Section, Centre for Advanced Technology, Indore 452 013, India
}

MS received 21 April 2001

\begin{abstract}
A simple method for the analysis of stainless steel samples is presented which is based on radioisotope excited energy dispersive $X$-ray fluorescence (EDXRF) spectrometry and does not require any type-standards. Both absorption and enhancement effects have been taken into account in the fundamental parameter method for quantitative analysis and an iterative approach is followed for calculation of concentrations in steel samples. Non-linear least square fitting (NL-LSF) procedures have been used to determine accurately the fluorescent peak intensities. The method has been tested by analysing several CRM standard reference samples and 304 and 316 steel samples assuming as unknown. The EDXRF results have also been compared with the results of analysis of same samples by vacuum emission spark spectrometry (VES). Obtained values for concentration in steel samples match quite well with their certified values.
\end{abstract}

Keywords. XRF; spectrometry; least squares fitting; stainless steel.

\section{Introduction}

Energy dispersive X-ray fluorescence (EDXRF) technique has become a powerful technique for non-destructive multielement analysis of materials. Over the last years, several developments have taken place in the methodology for quantitative analysis using this technique with the aim, on the one hand, to enhance the quality and reliability of the results, and to extend the range of its applications on the other hand. With the use of empirical and semi empirical algorithms (Lachance and Traill 1966; Claisse and Quintin 1967; Rasberry and Heinrich 1974), the elemental composition of the sample is determined by measuring the relative intensities of the X-ray fluorescent peaks with that of a set of multielement standards or pure elements. The comparative standards are desirable to be similar in shape, form and concentration to the unknown sample that sometimes limits the application of EDXRF due to the non-availability of such standards. The fundamental parameter method (FP) using iterative approach is a fast method (Sparks 1975; Sawhney and Lodha 1989) which can work even when type-standards are not available. This method gives reliable results for both trace and major element analysis provided the absorption and enhancement by the sample matrix is accounted for properly (Van Dyck et al 1986). The analysis of multicomponent alloys like stainless steel (SS), in which both trace and bulk elements are required to be determined, is

\footnotetext{
*Author for correspondence
}

some what complex as not only the matrix absorptionenhancement effects have to be corrected, but accurate peak intensities have to be determined from the complex spectra using some fitting procedures. Generally in stainless steel (SS) samples $\mathrm{Ti}(0 \cdot 03-0 \cdot 08), \mathrm{Si}(0 \cdot 03-1 \cdot 1)$, $\mathrm{C}(0 \cdot 03-0 \cdot 06), \mathrm{P}(0 \cdot 005-0 \cdot 035), \mathrm{S}(0 \cdot 005-0 \cdot 012), \mathrm{W}(0 \cdot 02-$ $0.3 \%)$ etc are present as minor components while $\mathrm{Cr}(3 \cdot 2-24 \cdot 4), \mathrm{Ni}(3 \cdot 7-21 \cdot 5), \mathrm{Fe}(50 \cdot 0-70 \cdot 0), \mathrm{Cu}(0 \cdot 6-2 \cdot 2)$ and $\mathrm{Mo}(1 \cdot 5-4.0 \%)$ are present as major components. Barrea and Mainardi (1998) have analysed the stainless steel samples by measuring two fluorescence spectra of same sample under two different excitation conditions, which provides a system of non-linear equations. Because two measurements are required to be done for each sample, the analysis time gets doubled in this method and moreover this method cannot be used in radioisotope excited XRF where the excitation energy is quasimonochromatic. They could determine elements $\mathrm{Cr}, \mathrm{Fe}$, $\mathrm{Ni}, \mathrm{Nb}$, Mo only. They could not determine the concentration of minor elements like $\mathrm{Mn}, \mathrm{Co}, \mathrm{Cu}$ etc whose $\mathrm{K}_{\alpha}$ peaks strongly overlapped with the neighbouring major peaks.

In the present paper, we present a method for stainless steel analysis which is simple, fast, non-destructive and does not require any type-standards. We have determined elements $\mathrm{Cr}, \mathrm{Mn}, \mathrm{Fe}, \mathrm{Co}, \mathrm{Ni}, \mathrm{Cu}, \mathrm{Nb}$, Mo etc in the stainless steel samples. The quantitative analysis has been performed by our in-house developed CATXRF program (Tiwari and Sawhney 2000), which is based on FP method and corrects for both absorption and enhancement effects. The peak areas have been determined by the use of non- 
linear least square fitting (NL-LSF) procedures. Only one single element standard has been used for the determination of system geometry factor. To verify the method, it has been applied for the analysis of several certified reference materials (CRM) and SS-304 and SS-316 samples and the results obtained from our method have also been compared with the analytical results obtained by the analysis of same samples by vacuum spark emission spectrometry (VES).

\section{Theory}

For monochromatic excitation, the measured X-ray fluorescence intensity, $I_{j}$, is related to the analyte mass, $m_{j}$, by (Sparks 1975)

$$
\left(I_{j}\right)_{k}=I_{0} G \cdot K_{j} \cdot A \cdot m_{j} \cdot\left(1+H_{j k}\right),
$$

where $K_{j}$ is the relative efficiency to excite and detect the fluorescent $\mathrm{X}$-rays from element $j$ and is given by

$$
K_{j}=\tau\left\{1-\frac{1}{J_{K, L}}\right\} \cdot \omega_{k} \cdot \varepsilon \cdot T \cdot f,
$$

$A$ is the mass absorption correction factor and for infinitely thick samples, in which domain the stainless steel samples fall, is given by

$$
A=\frac{1}{\left[\mu\left(E_{0}\right) \operatorname{cosec}\left(\psi_{1}\right)+\mu\left(E_{j}\right) \operatorname{cosec}\left(\psi_{2}\right)\right]},
$$

$H_{j k}$ is the enhancement factor and its value is zero for elements that are not enhanced by any other sample constituent. $H_{j k}$ for infinitely thick samples is given by Sparks (1975) as

$$
\begin{gathered}
H_{j k}=\frac{1}{2 \tau_{i}\left(E_{0}\right)} \sum_{k=1}^{m} W_{k} \cdot \omega_{k} \cdot\left(1-\frac{1}{J_{k l}}\right) \cdot \mu_{j}\left(E_{k}\right) \cdot \mu_{k}\left(E_{0}\right) \\
\cdot\left[\frac{\log \left(1+\frac{\mu\left(E_{0}\right)}{\mu\left(E_{k}\right) \cdot \sin \varphi_{1}}\right)}{\frac{\mu\left(E_{0}\right)}{\sin \varphi_{1}}}+\frac{\log \left(1+\frac{\mu\left(E_{j}\right)}{\mu\left(E_{k}\right) \cdot \sin \varphi_{2}}\right)}{\frac{\mu\left(E_{j}\right)}{\sin \varphi_{2}}}\right]
\end{gathered}
$$

where $j, k=$ index of the analyte and enhancing element; $E_{0}, E_{j}$, and $E_{k}$ are the energies of primary radiation and characteristic energies of the $j$ th and $k$ th elements, $\Psi_{1}, \Psi_{2}$ represent entrance and exit angles, $G_{0}$ a geometrical factor, $I_{0}$ the intensity of primary radiation, $\varepsilon$ the detector efficiency at the fluorescent energy $E_{j}, \tau$ the photoelectric mass absorption coefficient at primary energy, $J_{K, L}$ the jump ratio for the appropriate ( $K$ or $L$ ) absorption edge, $T$ the transmission coefficient of the fluorescent X-rays in the air path, $f$ the fractional intensity of the $\mathrm{X}$-ray line used for analysis, e.g $K_{\alpha} /\left(K_{\alpha}+K_{\beta}\right) . \mu\left(E_{0}\right), \mu\left(E_{j}\right), \mu\left(E_{k}\right)$ are the total sample mass absorption coefficients for X-ray energies $E_{0}, E_{j}$ and $E_{k}$ respectively, $W_{k}$ is the weight fraction of the $k$ th element, and $M$ is mass of sample in $\mathrm{g} / \mathrm{cm}^{2}$.

\section{Experimental}

Several CRM stainless steel samples and unknown samples were analysed on our EDXRF spectrometer (Sawhney et al 1998) consisting of a $\mathrm{Si}(\mathrm{Li})$ detector having an energy resolution of $155 \mathrm{eV}$ at $5.9 \mathrm{keV}$. A $20 \mathrm{mCi} \mathrm{Cd}^{109}$ annular radioisotope was used as an excitation source. The experimental setup is shown schematically in figure 1 . A $3 \mathrm{~mm}$ thick aluminum mask having a centred hole of diameter $24.7 \mathrm{~mm}$ was used to ensure same illuminated surface area for all the samples. The sample-detector and excitation source-sample distances were optimized to get maximum count rate in the fluorescent peaks. Each sample was analysed for $1000 \mathrm{sec}$. The EDXRF spectra of SS samples are quite complex because of the presence of several small peaks from minor elements occurring near the big peaks of major elements and a simple deconvolution procedure cannot be used to derive the peak areas of such small peaks. Examples of such strong peak overlapping are the pairs of spectral lines $\mathrm{Mn} \mathrm{K}_{\alpha}-\mathrm{Cr} \mathrm{K}_{\beta}, \mathrm{Co} \mathrm{K}_{\alpha}-\mathrm{Fe} \mathrm{K}_{\beta}$ and $\mathrm{Cu} \mathrm{K} \mathrm{K}_{\alpha}-\mathrm{Ni} \mathrm{K}_{\beta}$. Therefore to derive accurate peak areas of such strongly overlapped peaks, we have used non-linear least square fitting method using ORIGIN software (Microcal Origin USA, 1995, Technical Graphics and Data Analysis Software). Two typical fluorescence spectra of T-216 and SS-304 samples are shown in figures 2 and 3 . The system geometrical factor $I_{0} G$ was determined by analysing a single element synthetic standard. To confirm the value of $I_{0} G$, a few more synthetic standards of different elements in various

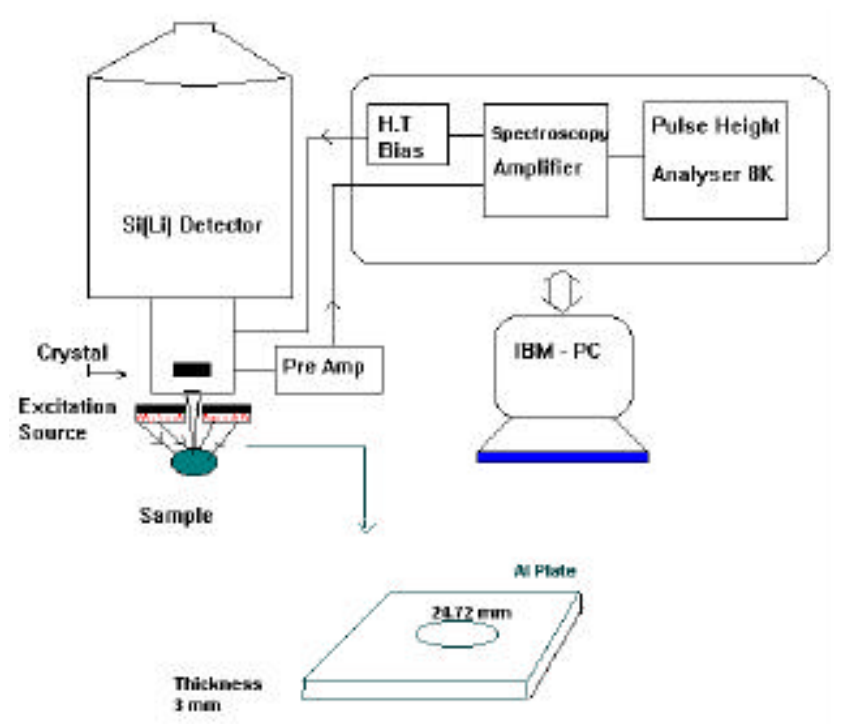

Figure 1. Schematic diagram of the experimental setup. 
concentrations were prepared and analysed and $I_{0} G$ was found to be reproducible within $\pm 2 \%$. All synthetic standards were prepared as pellets of diameter $24.7 \mathrm{~mm}$ from appropriate oxides. Quantitative analysis of all the SS samples was performed by the computer program CATXRF which is based on FP method and uses an iterative procedure to calculate the concentration of various elements present in the specimen. This program is written in FORTRAN-77 and runs on Pentium PCs. Details of the program are given elsewhere (Tiwari and Sawhney 2000). We have detected almost all the elements with $\mathrm{Z}>17$ present in steel samples, and the combined concentration of all other elements $(\mathrm{C}, \mathrm{P}, \mathrm{Si}, \mathrm{S}$ etc) which cannot be detected by EDXRF spectrometry, is less than $1 \%$. Hence no significant error is introduced in the elemental analysis if the presence of these low-Z elements is ignored. Accordingly it is assumed in our EDXRF quantitative analysis that the total concentration of all elements detected by EDXRF is $100 \%$. In the iterative procedure in CATXRF program, for the starting values, the specimen was assumed to comprise of $\mathrm{Fe}$ and cellulose in $1: 1$ ratio and the iteration was stopped when total concentration of all detected elements became $100 \%$. The values of various fundamental parameters were taken from published literature (McMaster et al 1969; Bambynek et al 1972).

\section{Results and discussion}

Figure 2a shows a typical fluorescence spectrum of a T216 reference sample obtained with EDXRF spectro-
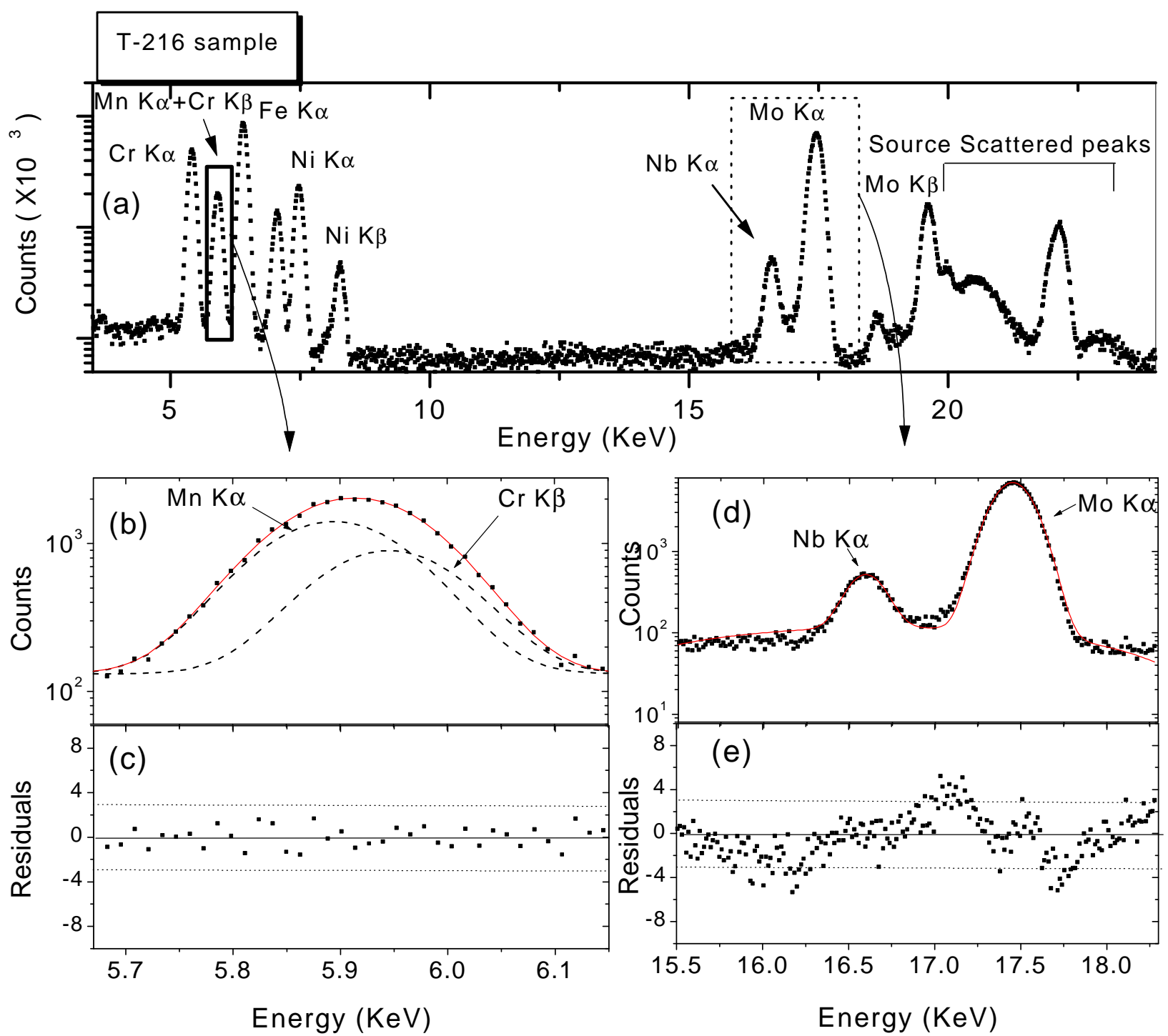

Figure 2. (a) A typical EDXRF spectra of T-216 SS-reference sample, (b) merged $\mathrm{Mn}-\mathrm{K}_{\alpha}$ and $\mathrm{Cr}-\mathrm{K}_{\beta} \mathrm{X}$-ray peaks fitted using NL-LSF procedures, (c) residuals of the fit in (b) in units of one standard deviation $(\sigma=\sqrt{N}$, where $N$ is the counts accumulated in a given energy channel) of data; similarly (d) and (e) show fitting results obtained for Nb-Mo pair. 


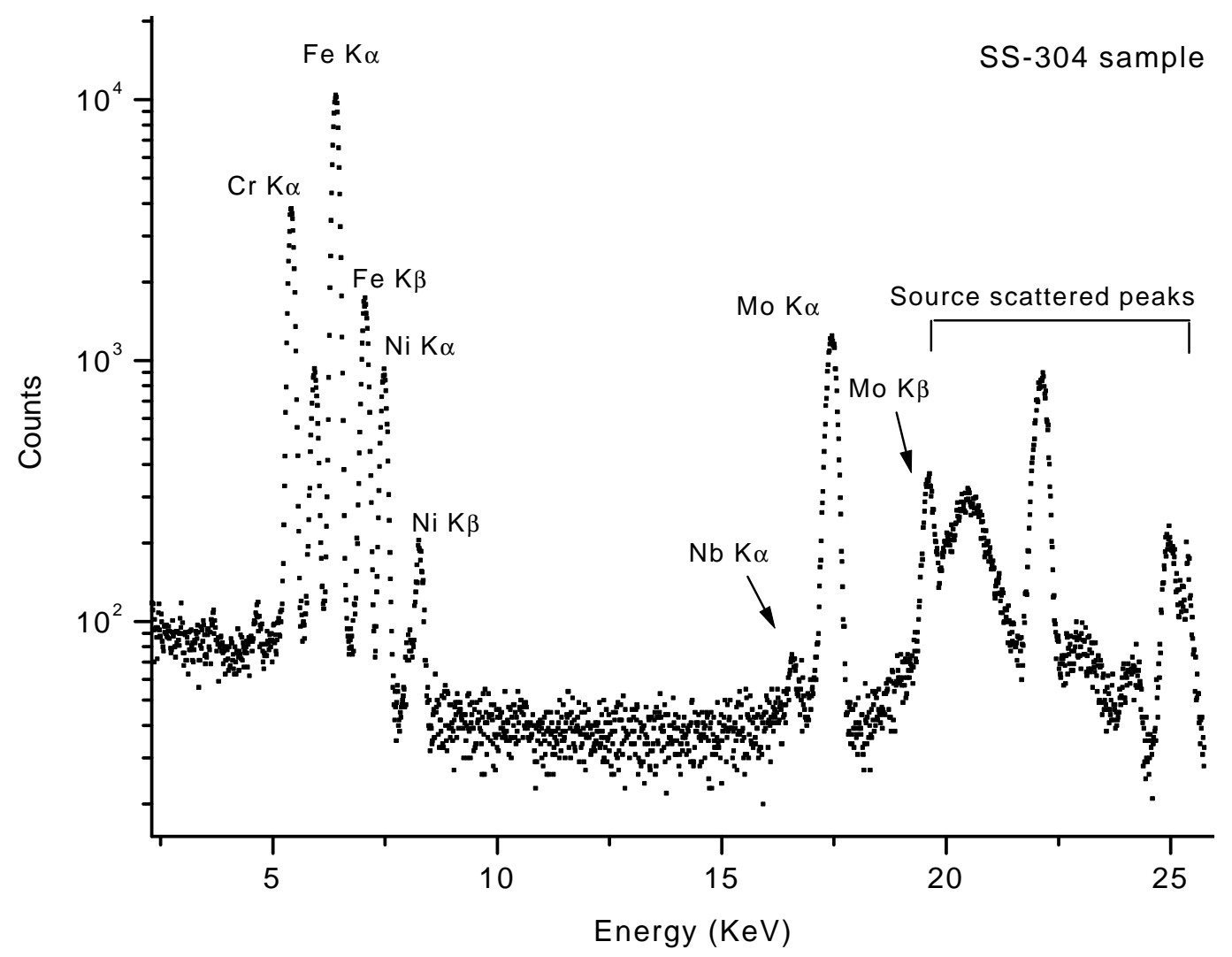

Figure 3. A typical EDXRF spectra of SS-304 sample.

meter. It is evident from the figure that the spectrum is quite complex with several peaks strongly overlapping. Owing to the complexity of the SS spectrum, the least squares fitting was done by dividing the spectrum into several regions. For instance figure $2 \mathrm{~b}$ shows the $\mathrm{Cr}-\mathrm{Mn}$ part of the spectrum for which the individual peak areas could only be derived by the use of NL-LSF procedure. The goodness of the fit is evident from figure $2 \mathrm{c}$ where the residuals of the fit are seen to fall within the $\pm 3 \sigma$ limit (Van Grieken and Markowicz 1993). Similarly the fitting results obtained for the $\mathrm{Nb}-\mathrm{Mo}$ part are shown in figures $2 \mathrm{~d}$ and e. The $\mathrm{Nb}-\mathrm{Mo}$ peaks fall on the tail of the broad Compton scattered source peak and hence the least squares fitting is not that perfect in this region which is reflected in relatively higher fitting residuals (figure 2e). Barrea and Mainardi (1998) could not determine the concentrations of minor elements like $\mathrm{Mn}, \mathrm{Co}, \mathrm{Cu}, \mathrm{Nb}$, etc because of strong overlaps and also non-correction of this type of overlaps $\left(K_{\beta}\right.$ line of one element merging in $\mathrm{K}_{\alpha}$ intensity of another element) results in greater error in their analysis. On the other hand we have been able to determine accurately the concentrations of all elements detectable by EDXRF technique.

The concentrations of minor and major elements in various SS samples analysed by EDXRF technique are given in tables 1 and 2 . Tables show that the concentration of all elements in each sample matches quite well with their certified values. The overall relative analysis error range from $2 \%$ to $10 \%$, which include errors contributed by geometrical reproducibility, counting statistics, errors in fundamental constants etc. The dominant error is the statistical error in the peak intensity determination which is higher for elements present in lower concentration. Various SS samples analysed by EDXRF technique were also analysed by VES (Vacuum Emission Spark Spectrometer, Model JY56E, Jobin Yvon, France). VES is an instrumental technique which is used in the elemental analysis of SS types of samples. The results of this analysis are also given in tables 1 and 2 . These tables show that the EDXRF results are similar to VES results and in many cases the EDXRF results match with certified values better than VES results. VES technique is a destructive technique as it creates a spark spot on the sample surface and also requires several type-standards similar in concentration and form of the unknown samples for the calibration of the spectrometer. On the other hand, the method reported here based on EDXRF technique does not require any type-standards and is applicable for all types of steel samples. The main advantage of VES technique is that it also gives the concentrations of low $\mathrm{Z}$ elements like $\mathrm{C}, \mathrm{P}, \mathrm{Si}$ etc which are not detectable by EDXRF measurements. For most of the routine analysis of SS the analysis can be performed by EDXRF, which is 
Table 1. Concentrations of CRM samples determined by EDXRF and VES.

\begin{tabular}{|c|c|c|c|c|}
\hline \multirow{2}{*}{$\begin{array}{l}\text { Sample } \\
\text { no. }\end{array}$} & \multirow[b]{2}{*}{ Elements } & \multicolumn{3}{|c|}{ Concentrations (\%) } \\
\hline & & Certified & By EDXRF & By VES \\
\hline \multirow[t]{6}{*}{ T-211 } & $\mathrm{Cr}$ & $19 \cdot 50$ & $19 \cdot 1 \pm 0 \cdot 40$ & $18 \cdot 4 \pm 0 \cdot 30$ \\
\hline & $\mathrm{Mn}$ & $1 \cdot 80$ & $1.84 \pm 0.08$ & $1.60 \pm 0.05$ \\
\hline & $\mathrm{Fe}$ & $69 \cdot 56$ & $69 \cdot 9 \pm 1 \cdot 60$ & $69.9 \pm 1.00$ \\
\hline & $\mathrm{Ni}$ & $8 \cdot 61$ & $8 \cdot 4 \pm 0 \cdot 20$ & $8 \cdot 6 \pm 0 \cdot 10$ \\
\hline & $\mathrm{Cu}$ & $0 \cdot 20$ & $1381 \pm 50 \quad \mathrm{ppm}$ & - \\
\hline & Mo & $0 \cdot 20$ & $0 \cdot 21 \pm 0.02$ & - \\
\hline \multirow{8}{*}{$\mathrm{T}-212$} & $\mathrm{Cr}$ & $21 \cdot 80$ & $21 \cdot 4 \pm 0 \cdot 50$ & $21 \cdot 4 \pm 0 \cdot 30$ \\
\hline & $\mathrm{Mn}$ & $0 \cdot 83$ & $0.9 \pm 0.05$ & $0.77 \pm 0.02$ \\
\hline & $\mathrm{Fe}$ & $65 \cdot 40$ & $65 \cdot 1 \pm 1 \cdot 50$ & $67 \cdot 6 \pm 1.00$ \\
\hline & Co & $0 \cdot 18$ & $1630 \pm 150 \mathrm{ppm}$ & - \\
\hline & $\mathrm{Ni}$ & $7 \cdot 12$ & $7 \cdot 1 \pm 0 \cdot 20$ & $6 \cdot 5 \pm 0 \cdot 10$ \\
\hline & $\mathrm{Cu}$ & $1 \cdot 37$ & $1.36 \pm 0.05$ & - \\
\hline & $\mathrm{Nb}$ & $0 \cdot 01$ & $192 \pm 18 \quad \mathrm{ppm}$ & - \\
\hline & Mo & $2 \cdot 50$ & $2 \cdot 5 \pm 0.05$ & $2 \cdot 3 \pm 0 \cdot 05$ \\
\hline \multirow{8}{*}{$\mathrm{T}-213$} & $\mathrm{Cr}$ & $21 \cdot 60$ & $22 \cdot 0 \pm 0 \cdot 50$ & $21 \cdot 6 \pm 0.33$ \\
\hline & $\mathrm{Mn}$ & $1 \cdot 07$ & $1.0 \pm 0.05$ & $1 \cdot 0 \pm 0.03$ \\
\hline & $\mathrm{Fe}$ & $64 \cdot 90$ & $65 \cdot 2 \pm 1 \cdot 50$ & $67 \cdot 3 \pm 1 \cdot 00$ \\
\hline & Co & $0 \cdot 26$ & $0.4 \pm 0.04$ & - \\
\hline & $\mathrm{Ni}$ & $7 \cdot 24$ & $7 \cdot 2 \pm 0 \cdot 20$ & $6 \cdot 2 \pm 0 \cdot 10$ \\
\hline & $\mathrm{Cu}$ & $1 \cdot 50$ & $1.5 \pm 0.05$ & - \\
\hline & $\mathrm{Nb}$ & 0.03 & $417 \pm 40 \quad \mathrm{ppm}$ & - \\
\hline & Mo & $2 \cdot 53$ & $2 \cdot 56 \pm 0 \cdot 06$ & $2 \cdot 37 \pm 0.05$ \\
\hline \multirow{8}{*}{$\mathrm{T}-214$} & $\mathrm{Cr}$ & $20 \cdot 12$ & $20 \cdot 0 \pm 0 \cdot 40$ & $20 \cdot 3 \pm 0 \cdot 30$ \\
\hline & $\mathrm{Mn}$ & 1.45 & $1.49 \pm 0.06$ & $1.43 \pm 0.04$ \\
\hline & $\mathrm{Fe}$ & $47 \cdot 80$ & $47 \cdot 9 \pm 1 \cdot 10$ & $48 \cdot 6 \pm 0 \cdot 70$ \\
\hline & Co & $0 \cdot 29$ & $0.37 \pm 0.03$ & - \\
\hline & $\mathrm{Ni}$ & $24 \cdot 44$ & $23 \cdot 9 \pm 0 \cdot 60$ & $23 \cdot 9 \pm 0 \cdot 40$ \\
\hline & $\mathrm{Cu}$ & 1.42 & $1.49 \pm 0.05$ & - \\
\hline & $\mathrm{Nb}$ & $0 \cdot 01$ & $226 \pm 21 \quad \mathrm{ppm}$ & - \\
\hline & Mo & $4 \cdot 24$ & $4 \cdot 28 \pm 0.09$ & $4 \cdot 53 \pm 0 \cdot 10$ \\
\hline \multirow{8}{*}{$\mathrm{T}-215$} & $\mathrm{Cr}$ & $18 \cdot 63$ & $19 \cdot 4 \pm 0 \cdot 40$ & $18 \cdot 7 \pm 0.28$ \\
\hline & $\mathrm{Mn}$ & $1 \cdot 38$ & $1.4 \pm 0.06$ & $1.50 \pm 0.05$ \\
\hline & $\mathrm{Fe}$ & $65 \cdot 40$ & $65 \cdot 0 \pm 1 \cdot 50$ & $65 \cdot 7 \pm 1 \cdot 00$ \\
\hline & Co & $0 \cdot 01$ & $1451 \pm 133 \mathrm{ppm}$ & - \\
\hline & $\mathrm{Ni}$ & $10 \cdot 95$ & $10 \cdot 9 \pm 0 \cdot 30$ & $10 \cdot 6 \pm 0 \cdot 20$ \\
\hline & $\mathrm{Cu}$ & $0 \cdot 02$ & $495 \pm 18 \cdot 0 \mathrm{ppm}$ & - \\
\hline & $\mathrm{Nb}$ & $0 \cdot 76$ & $0.81 \pm 0.07$ & - \\
\hline & Mo & $2 \cdot 20$ & $2 \cdot 3 \pm 0.05$ & $2 \cdot 16 \pm 0 \cdot 04$ \\
\hline \multirow[t]{8}{*}{ T-216 } & $\mathrm{Cr}$ & $23 \cdot 40$ & $23 \cdot 0 \pm 0.53$ & $23 \cdot 6 \pm 0 \cdot 35$ \\
\hline & $\mathrm{Mn}$ & $5 \cdot 60$ & $5 \cdot 8 \pm 0 \cdot 25$ & $5 \cdot 6 \pm 0 \cdot 14$ \\
\hline & $\mathrm{Fe}$ & $50 \cdot 76$ & $50 \cdot 3 \pm 1 \cdot 10$ & $50 \cdot 9 \pm 0 \cdot 70$ \\
\hline & Co & $0 \cdot 16$ & $0.25 \pm 0.02$ & - \\
\hline & $\mathrm{Ni}$ & $16 \cdot 30$ & $16 \cdot 7 \pm 0 \cdot 40$ & $15 \cdot 2 \pm 0 \cdot 20$ \\
\hline & $\mathrm{Cu}$ & $0 \cdot 15$ & $0 \cdot 21 \pm 0 \cdot 01$ & - \\
\hline & $\mathrm{Nb}$ & $0 \cdot 24$ & $0.24 \pm 0.02$ & - \\
\hline & Mo & $2 \cdot 92$ & $3 \cdot 0 \pm 0 \cdot 10$ & $2.9 \pm 0.06$ \\
\hline \multirow[t]{7}{*}{ CRM-474 } & $\mathrm{Cr}$ & $19 \cdot 06$ & $19 \cdot 8 \pm 0.45$ & $18 \cdot 7 \pm 0 \cdot 28$ \\
\hline & $\mathrm{Mn}$ & 1.70 & $1.68 \pm 0.07$ & $1 \cdot 71 \pm 0.04$ \\
\hline & $\mathrm{Fe}$ & $60 \cdot 05$ & $59 \cdot 5 \pm 1.40$ & $60 \cdot 5 \pm 1 \cdot 00$ \\
\hline & $\mathrm{Ni}$ & $14 \cdot 70$ & $14 \cdot 8 \pm 0 \cdot 40$ & $15 \cdot 1 \pm 0 \cdot 30$ \\
\hline & $\mathrm{Cu}$ & $0 \cdot 35$ & $0 \cdot 35 \pm 0 \cdot 01$ & - \\
\hline & $\mathrm{Nb}$ & 0.01 & $157 \pm 14.0 \mathrm{ppm}$ & - \\
\hline & Mo & $3 \cdot 55$ & $3.7 \pm 0.08$ & $3 \cdot 71 \pm 0.07$ \\
\hline \multirow[t]{7}{*}{ CRM-475 } & $\mathrm{Cr}$ & $14 \cdot 14$ & $14 \cdot 4 \pm 0 \cdot 30$ & $14 \cdot 3 \pm 0 \cdot 22$ \\
\hline & $\mathrm{Mn}$ & $0 \cdot 89$ & $0 \cdot 86 \pm 0 \cdot 02$ & $0.96 \pm 0.02$ \\
\hline & $\mathrm{Fe}$ & $75 \cdot 00$ & $75 \cdot 3 \pm 1 \cdot 70$ & $77 \cdot 0 \pm 1 \cdot 00$ \\
\hline & Co & $0 \cdot 22$ & $0 \cdot 3 \pm 0 \cdot 03$ & - \\
\hline & $\mathrm{Ni}$ & $5 \cdot 66$ & $5 \cdot 7 \pm 0 \cdot 15$ & $5 \cdot 63 \pm 0 \cdot 10$ \\
\hline & $\mathrm{Nb}$ & $0 \cdot 22$ & $0 \cdot 23 \pm 0.02$ & - \\
\hline & Mo & $1 \cdot 59$ & $1 \cdot 61 \pm 0.04$ & $1.6 \pm 0.03$ \\
\hline
\end{tabular}


Table 2. Concentrations of SS-304 and SS-316 samples determined by EDXRF and VES.

\begin{tabular}{|c|c|c|c|c|}
\hline \multirow{2}{*}{$\begin{array}{l}\text { Sample } \\
\text { no. }\end{array}$} & \multirow[b]{2}{*}{ Elements } & \multicolumn{3}{|c|}{ Concentrations (\%) } \\
\hline & & Certified range & By EDXRF & By VES \\
\hline \multirow[t]{7}{*}{ SS-304 } & $\mathrm{Cr}$ & $18 \cdot 0-20 \cdot 0$ & $18 \cdot 9 \pm 0 \cdot 40$ & $18 \cdot 0 \pm 0.27$ \\
\hline & $\mathrm{Mn}$ & 2.0 Max. & $1.23 \pm 0.05$ & $1.27 \pm 0.03$ \\
\hline & $\mathrm{Fe}$ & $60 \cdot 0-70 \cdot 0$ & $69 \cdot 9 \pm 1 \cdot 60$ & $70 \cdot 0 \pm 1 \cdot 00$ \\
\hline & $\mathrm{Ni}$ & $8 \cdot 0-12 \cdot 0$ & $8 \cdot 9 \pm 0 \cdot 20$ & $8 \cdot 0 \pm 0 \cdot 10$ \\
\hline & $\mathrm{Cu}$ & - & $0 \cdot 3 \pm 0 \cdot 01$ & - \\
\hline & $\mathrm{Nb}$ & - & $131 \pm 20 \cdot 0 \mathrm{ppm}$ & - \\
\hline & Mo & - & $0.6 \pm 0.01$ & $0.33 \pm 0.01$ \\
\hline \multirow[t]{7}{*}{ SS-316 } & $\mathrm{Cr}$ & $16 \cdot 0-18 \cdot 0$ & $17 \cdot 5 \pm 0 \cdot 40$ & $16 \cdot 8 \pm 0 \cdot 24$ \\
\hline & $\mathrm{Mn}$ & 2.0 Max. & $1.56 \pm 0.07$ & $1 \cdot 34 \pm 0 \cdot 03$ \\
\hline & $\mathrm{Fe}$ & $60 \cdot 0-70 \cdot 0$ & $67 \cdot 1 \pm 1 \cdot 52$ & $67 \cdot 4 \pm 1.00$ \\
\hline & $\mathrm{Co}$ & - & $0.25 \pm 0.02$ & - \\
\hline & $\mathrm{Ni}$ & $10 \cdot 0-14 \cdot 0$ & $10 \cdot 9 \pm 0 \cdot 30$ & $10 \cdot 5 \pm 0 \cdot 20$ \\
\hline & $\mathrm{Cu}$ & - & $0.28 \pm 0.01$ & - \\
\hline & Mo & $2 \cdot 0-3 \cdot 0$ & $2 \cdot 3 \pm 0.05$ & $2 \cdot 23 \pm 0 \cdot 04$ \\
\hline
\end{tabular}

seen to give good results by the method of analysis reported in this paper.

In general, in XRF analysis of stainless steel types of samples, where several high $\mathrm{Z}$ elements are present in sufficiently high concentration, the enhancement effect becomes quite dominant and can give erroneous results if it is not corrected for mathematically. For example in SS, $\mathrm{Cr}$ is strongly enhanced by $\mathrm{Fe}$ and can yield inflated values for $\mathrm{Cr}$ concentration by as much as $40-60 \%$ if not properly corrected. In our CATXRF program both matrix absorption and enhancement effects are properly corrected as per the equations given in the theory section.

\section{Conclusions}

In this paper a simple method for non-destructive and standardless analysis of stainless steel samples is presented. The agreement between the calculated concentrations and certified concentration values of various elements in different stainless steel samples have demonstrated that the compositional analysis of stainless steel samples can be made reliably with a simple radioisotope excited EDXRF system. The CATXRF quantitative analysis program in conjunction with the non-linear least square fitting method gives a simple, fast, standardless, nondestructive method of SS analysis. The system described has provided our laboratory with an inexpensive alternative to the more commonly used VES system for SS analysis. The method reported here can also be used for materials other than steel.

\section{References}

Barrea Raul A and Mainardi Raul T 1998 X-ray Spectrom. 27 111

Bambynek W, Crasemann B, Fink R W, Freund H U, Swift C D, Price R E and Rao P V 1972 Rev. Mod. Phys. 44716

Claisse F and Quintin M 1967 Can. Spectrosc. 12129

Lachance G R and Traill R J 1966 Can. Spectrosc. 1143

McMaster W H, Delgrande N K and Hubbell J H 1969 Compilation of X-ray cross sections, UCRL-50174 (Livermore: Lawrence Radiation Laboratory, Univ. California) p. 353

Rasberry S D and Heinrich K F J 1974 Anal. Chem. 4681

Sawhney K J S and Lodha G S 1989 Computers and Geosciences 151115

Sawhney K J S, Tiwari M K, Singh A K and Nandedkar R V 1998 Proc. 6th national seminar on X-ray spectroscopy and allied areas (eds) S K Joshi et al (New Delhi: Narosa) p. 130

Sparks C J Jr 1975 Adv. X-ray Anal. 1919

Tiwari M K and Sawhney K J S 2000 CATXRF: A quantitative analysis program for EDXRF spectrometry, CAT technical report

Van Dyck P M, Torok Sz B and Van Grieken R E 1986 Anal. Chem. 581761

Van Grieken R E and Markowicz A A 1993 Handbook of X-ray spectrometry (New York: Marcel Dekker) p. 181 